\title{
Efficiency of night ventilation in limiting the overheating of passive sports hall
}

\author{
Anna Dudzińska ${ }^{1}$, Tomasz Kisilewicz ${ }^{1, *}$ \\ ${ }^{1}$ Cracow University of Technology, Chair of Building Design and Building Physics, Faculty of Civil \\ Engineering, Warszawska 24, 31-155 Cracow, Poland
}

\begin{abstract}
It is especially difficult to provide optimal microclimatic conditions in sports facilities during summer time. The internal heat gains and an airtight building insulation, combined with high external temperature can easily lead to overheating and upsetting of the body's thermal balance. This article focuses primarily on the effect of natural night ventilation on the thermal comfort in a passive sports hall building. Based on experimental studies of thermal conditions in the hall, a simulation model was made using the Design Builder program. Through simulation analysis, the program considered thermal conditions that arise in various scenarios of natural and mechanical ventilation. Results presented in this article show that the natural ventilation at night in a large volume building is the most effective and the easiest way to reduce overheating in summer.
\end{abstract}

\section{Introduction}

Global warming and the extreme weather phenomena that have been intensifying in recent years affect all walks of our lives directly or indirectly. In the construction sector, it has become necessary to implement all solutions that allow for the design and operation of energy-efficient and ecological buildings, while ensuring adequate quality of the internal environment. Sports facilities with their specific microclimatic requirements due to the required operating temperature and physical activity of users pose a serious challenge for investors and managers. The additional criterion of low energy consumption in extremely tight and well insulated buildings often causes overheating of the interior. This leads to the users' discomfort and consequently, negative social attitude towards such technologies.

One of the ways to remove the energy accumulated in the roomy enclosures of the building and reduce the indoor temperature is night ventilation. Energy costs of mechanical cooling are minimized by night ventilation, and the reduced temperature of roomy enclosures can help in achieving thermal comfort during the next hot day $[1,2,3,4]$. The effectiveness of night ventilation depends on the local climate parameters, building parameters as well as technical parameters of the ventilation system (ventilation intensity at night and control strategy) $[5,6]$. The results presented in the article are aimed at checking

*Corresponding author: tkisilew@pk.edu.pl 
which of the night cooling methods is the most effective and easiest way to reduce overheating in summer in a low-energy sports facility with a large cubature.

\section{Study of the microclimate in a passive sports hall}

As part of the experimental studies, measurements were taken of the thermal comfort of the sports hall of the Agricultural University of Cracow, implemented in the passive energy standard (Fig. 1). The high energy standard allowed for a huge reduction in heating demand below $15 \mathrm{kWh} / \mathrm{m}^{2}$. The design assumptions regarding the amount of energy and winter microclimate were fully confirmed during the building's operation. However, since the passive standard is mainly oriented towards minimizing energy consumption in winter conditions, attempts have been made to assess the conditions in the building during the summer period.

The average annual air temperature in Cracow is $9.9^{\circ} \mathrm{C}$, the average of the warmest month (July) is $19.9^{\circ} \mathrm{C}$, and the maximum reported temperature was $38.4^{\circ} \mathrm{C}$. The monthly sum of total solar radiation in July is $597 \mathrm{MJ} / \mathrm{m}^{2}$.

The building has a footprint area of $1776.2 \mathrm{~m}^{2}$ which includes a multifunctional sports arena with stands for about 156 people and dressing room and sanitary facilities with accompanying rooms. The thermal transmittance coefficients of opaque partitions were around $0,087 \div 0,1 \mathrm{~W} /\left(\mathrm{m}^{2} \mathrm{~K}\right)$, and of external transparent partitions were $0.8 \mathrm{~W} /\left(\mathrm{m}^{2} \mathrm{~K}\right)$. High airtightness of external partitions in the hall of the University of Agriculture was confirmed by pressure test in accordance with PN-EN ISO 9972: 2015-10 and a result, of $\mathrm{n}_{50}=0.3 \mathrm{~h}^{-1}$ was obtained.

A mechanical supply/exhaust ventilation system with heat recovery with a maximum efficiency of $85 \%$ was designed and implemented in the sports facility. The facade and the roof of the hall were covered with vines and grassy plants, whose task, according to the architectural concept, is to prevent the hall from overheating. In order to protect the building against excessive solar gains, electric external shutters were also used (Fig. 1).
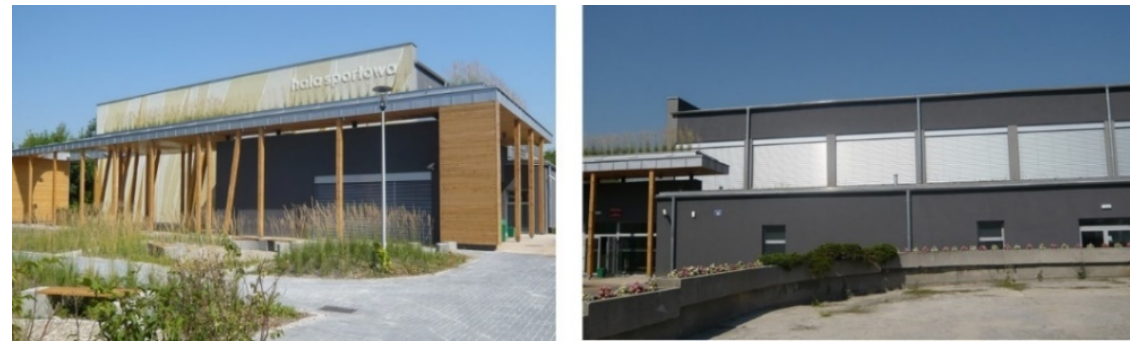

Fig. 1. Southern facade (left) and Eastern facade (right) (Author's archive)

Measurements in this facility were taken twice, during the highest thermal load. The first test measurements were taken (without users) in the period of 7-10 August 2013, the next in the period of 20-24 May 2014 (during sports activities in the hall), when the outdoor temperature was above $30^{\circ} \mathrm{C}$. For the first series of measurements, the hall was out of service, therefore neither mechanical nor natural ventilation was used, and windows were not opened. In this sense, the tested conditions are not reliable for the normal functioning of this building, but they characterize the natural (undisturbed operation of the installation) insulating and capacitive properties of the building. The second series of measurements was carried out in conditions consistent with the intended use of the sports facility. However, mechanical ventilation was activated only on the second day of measurements, every hour for 15-30 minutes if classes were taking place in the room. Windows were opened and closed manually, within the building's operating hours 8.00-22.00. 
The technical design of the Agricultural University hall perceived the use of a natural night interior ventilation system. The design concept consisted only of tilting windows on opposite walls of the sports arena and intensive cooling of the building at night with external air. However, during the microclimate tests carried out in the hall, this solution was not used.

Selected environmental parameters characterizing the internal environment in the hall during the tests are presented in Table 1.

Table 1. Average values of parameters of the internal environment

\begin{tabular}{|c|c|c|c|c|}
\hline \multirow[b]{2}{*}{ No. } & \multirow{2}{*}{$\begin{array}{l}\text { Parameters of the environment } \\
\text { (average values) }\end{array}$} & \multirow[b]{2}{*}{ Unit } & \multicolumn{2}{|c|}{ Sports hall AU } \\
\hline & & & $\begin{array}{c}\text { I } \\
\text { measurement }\end{array}$ & $\begin{array}{c}\text { II } \\
\text { measurement }\end{array}$ \\
\hline 1 & Indoor air temperature & {$\left[{ }^{\circ} \mathrm{C}\right]$} & 27.94 & 24.12 \\
\hline 2 & Indoor air humidity & {$[\%]$} & 58.28 & 50.85 \\
\hline 3 & Radiation temperature & {$\left[{ }^{\circ} \mathrm{C}\right]$} & 28.77 & 24.30 \\
\hline 4 & PMV & {$[-]$} & 1.14 & 2.26 \\
\hline 5 & PPD & {$[\%]$} & 33.15 & 84.18 \\
\hline
\end{tabular}

The average PMV values for both series of measurements were outside the Fanger thermal comfort limits $-0.5<\mathrm{PMV}<+0.5$ (Table 1). During the second series of measurements, when the hall was normally used, the value of the PMV index never fell below 1.6 and its limit value exceeded 3.0 (Fig. 2). From the third day of measurements, the PMV value exceeded the maximum permissible value of 2.0 .

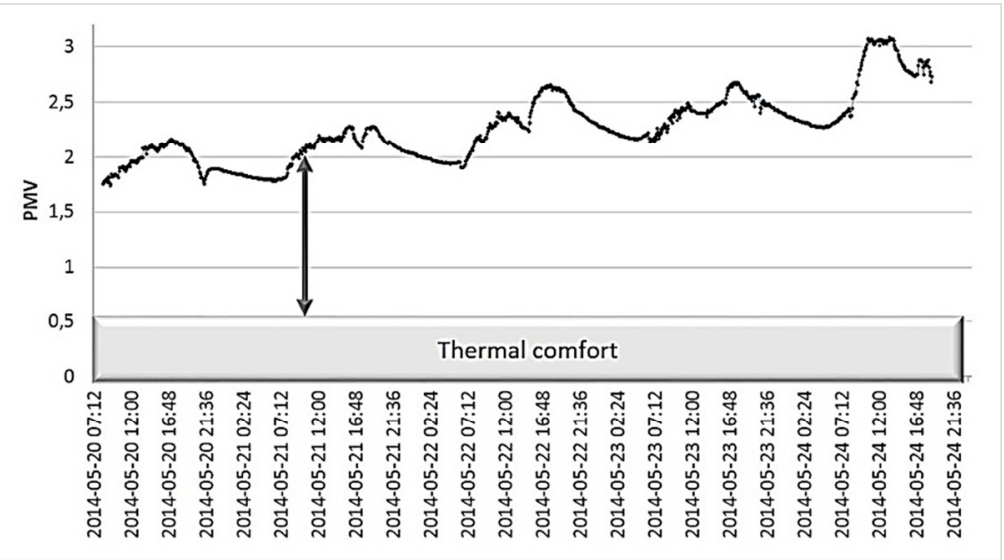

Fig.2. Distribution of PMV index values in the second measurement cycle

The unfavorable microclimate in the hall was caused not only by the high temperature of the outdoor air, but also by the way of operation. Little use of mechanical ventilation and the lack of night cooling led to the accumulation of excess energy in the building.

The Design Builder simulation program was used to test whether intense night cooling would allow for thermal comfort or at least a significant reduction in overheating. 


\section{Simulation analysis in a passive sports hall using the program 'Design Builder'}

\subsection{Assumptions for the simulation}

A model of the sports hall under study was created in Design Builder (Fig. 3). The model was validated by assessing the compliance of the simulation results with the results of measurements of the indoor air temperature in the analyzed hall in the second measurement period. The $r_{x y}$ correlation coefficient of 0.94 obtained during validation means a very high correlation in statistical analysis. Therefore, it was accepted that the model of a passive sports hall made in Design Builder could be used to conduct further analyses.

Due to the specific use of the object only during the academic year, simulations were carried out solely for the period from 01.05. until 30.06. Other summer months are not included due to the holiday period at this facility. The metabolic energy of a student, while exercising, was assumed to be $300 \mathrm{~W} /$ person. For the summer period analyzed, a value of thermal resistance of clothing corresponding to light sports clothing equal to 0.3 clo was introduced.
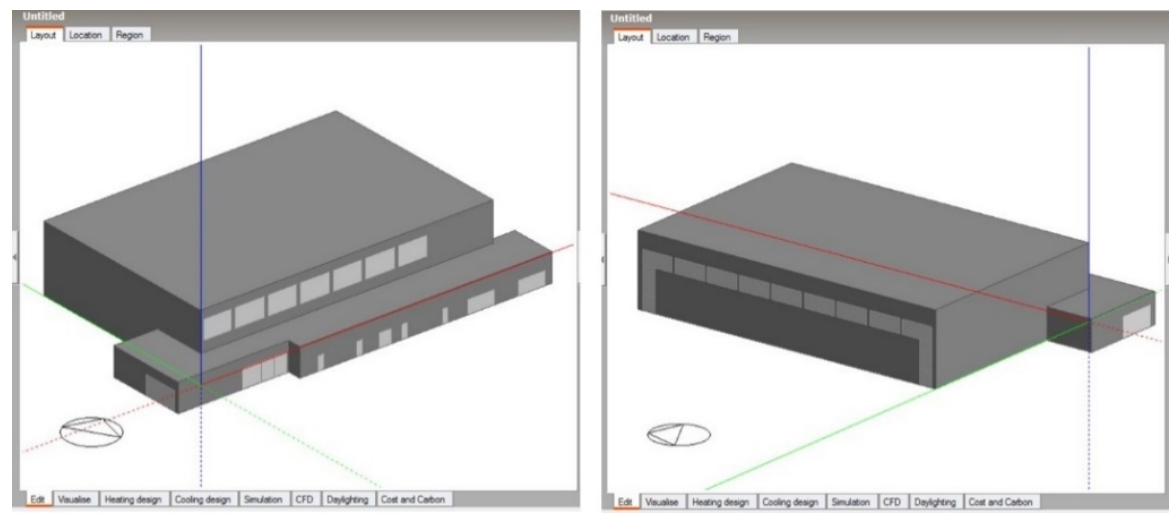

Fig. 3. South-east façade (left) and north-west façade (right) of the Agricultural University hall generated in Design Builder

Adhering to the factual way of using the hall during measurements, it was assumed that the blinds on the south-east facade are closed when the solar radiation intensity exceeds $100 \mathrm{~W} / \mathrm{m}^{2}$, and on the north-west side the blinds are open throughout the simulation period.

The required lighting intensity in the hall was adopted in accordance with PN-EN 12464-1: 2012 at the level of 400 lux. Artificial lighting is switched on automatically if natural lighting is insufficient during the operating hours of the room, i.e. 8.00-22.00.

The assumed way of using the room during the week is presented in tab. 2.

Table 2. Usage of the sports hall of the Agricultural University adopted for simulation

\begin{tabular}{|c|l|c|c|}
\hline No. & \multicolumn{1}{|c|}{ Day of the week } & Hours & People in the hall $/ \mathrm{h}$ \\
\hline \multirow{2}{*}{1} & \multirow{2}{*}{ Monday-Friday } & $8.00-16.00$ & 50 \\
\cline { 3 - 4 } & & $16.00-22.00$ & 25 \\
\hline 2 & Saturday-Sunday & $9.00-20.00$ & 50 \\
\hline
\end{tabular}

The design documentation of the building assumes the level of utilization of the ventilation unit depending on the use of the hall: 
- during competitions and when the stands are full - $100 \%$

- $1 / 3$ hall in use - $20 \%$

- 2 or 3 sectors occupied by spectators - 40 or $60 \%$ of maximum capacity.

The maximum capacity of the ventilation unit corresponds to the air exchange rate in the building equal to $0.75 \mathrm{ac} / \mathrm{h}$ (the maximum ventilation capacity is $9000 \mathrm{~m}^{3} / \mathrm{h}$ and the cubage of the hall is about $12075 \mathrm{~m}^{3}$ ). It was assumed that the minimum required fresh air flow for one player is $30 \mathrm{~m}^{3} / \mathrm{h}$, therefore air exchange at the level of $1500 \mathrm{~m}^{3} / \mathrm{h}$ would satisfy the hygiene needs of 50 players. The minimum fresh air flow must be provided by mechanical ventilation when the windows in the building are not open and there is no natural ventilation.

It was assumed that it is possible to open the windows all day (during the week between 8.00-22.00, on weekends between 8.00-20.00) on both sides of the arena (only 20\% of total opening). In the simulation, however, daily ventilation was made dependent on external conditions, i.e. if the condition $\mathrm{T}_{\text {out }}>\mathrm{T}_{\text {int }}$ is met - the windows are closed, where;

$\mathrm{T}_{\text {out }}$ - outdoor air temperature $\left[{ }^{\circ} \mathrm{C}\right]$

$\mathrm{T}_{\text {int }}$ - indoor air temperature $\left[{ }^{\circ} \mathrm{C}\right]$.

On the other hand, night-time natural ventilation means tilting windows $(20 \%$ or $40 \%$ opening) in simulations from 23:00 to 6:00. The outdoor air temperature at night in the twomonth period analyzed, dropped even to $+0.1^{\circ} \mathrm{C}(06.05$.). In order to avoid excessive cooling of the hall, the value adopted for the minimum indoor air temperature at which it is possible to tilt windows was equal to $14^{\circ} \mathrm{C}$.

The following variants of simulation were adopted:

- variant 1 - a starting point - mechanical ventilation switched off, natural ventilation during the day depending on external conditions (Tout> Tint - windows closed), no night ventilation. This variant is similar to the actual way of operating the hall and treated as a reference variant,

- variant 2 - mechanical ventilation switched off, daily natural ventilation depending on external conditions (Tout>Tint - windows closed), natural night ventilation used during hours. 23.00-6.00: $20 \%$ of the total tilt of all windows.

- variant 3 - similar to variant 2 , but night ventilation with $40 \%$ window tilt.

- variant 4 - mechanical ventilation switched on during the day from 9.00-16.00 at $20 \%$ of the maximum value, windows tilted during 8.00-9.00 and 16.00-22.00 on both sides of the arena, with the condition: Tout $>$ Tint - windows closed, no night ventilation.

- variant 5 - mechanical ventilation switched on during the day from 9.00-16.00 at 20\% of the maximum value, windows tilted during the hours 8.00-9.00 and 16.00-22.00 on both sides of the arena, in case of Tout>Tint - closed windows, natural night ventilation used during the hours $23.00-6.00: 40 \%$ of the total tilt of all windows.

\subsection{Results of simulation}

Table 3 summarizes the calculated values of some environmental parameters in the sports hall, obtained during the simulation of the 5 adopted variants of building use. The indoor air temperature for the five simulation variants adopted as well as the arithmetic mean values of the radiation temperature in the hall were taken into account.

There are no clear guidelines in the building regulations in Poland, regarding the temperature range of thermal comfort in sports facilities. The authors adopted their own requirements in this respect, based on the assumed level of metabolism and insulation of clothes and using the algorithm formulated by Fanger. It was assumed that indoor air temperatures, comfortable for active users of the hall in the summer, are in the range of 14$18^{\circ} \mathrm{C}$. 
The average indoor air temperatures in the adopted two-month analysis period are in the $17.0-21.6^{\circ} \mathrm{C}$ range for all variants. The average value of the indoor air temperature for variants 2,3 and 5 is in the range $17-17.6^{\circ} \mathrm{C}$. Considering the average and the highest temperature value of $27.3^{\circ} \mathrm{C}$, option 4 turns out to be the worst. Similarly, unfavorably high indoor air temperature values occur in option 1, which is closest to the factual use of the hall. The difference in average air temperature values between the best option No. 3 and the most unfavorable No. 4 is $4.6 \mathrm{~K}$.

In the case of radiative temperature, the highest average value in the entire two-month period occurs in variant 4 with mechanical ventilation switched on, but without night ventilation, and amounts to $22.3^{\circ} \mathrm{C}$. The lowest average value of radiation temperature $t_{r}$, equal to $18.3^{\circ} \mathrm{C}$ occurs in variant 3 , where mechanical ventilation is not used during the day and windows are tilted at night. The average indoor air humidity for none of the variants exceeded the recommended threshold of $70 \%$.

Table 3. Values for indoor air temperature, radiation temperature and indoor air humidity for the twomonth analysis period and the five adopted simulation variants

\begin{tabular}{|c|l|c|c|c|c|}
\hline \multirow{2}{*}{ No. } & \multirow{2}{*}{$\begin{array}{c}\text { Simulation } \\
\text { variants }\end{array}$} & \multicolumn{2}{|c|}{$\begin{array}{c}\text { Indoor air temperature } \\
\text { ta }\left[{ }^{\circ} \mathrm{C}\right]\end{array}$} & $\begin{array}{c}\text { Radiation temperature } \\
\operatorname{tr}\left[{ }^{\circ} \mathrm{C}\right]\end{array}$ & $\begin{array}{c}\text { Indoor air humidity } \\
{[\%]}\end{array}$ \\
\cline { 3 - 6 } & & average & highest & average & average \\
\hline 1 & variant 1 & 19.9 & 26.3 & 20.8 & 59.9 \\
\hline 2 & variant 2 & 17.5 & 24.0 & 18.7 & 67.9 \\
\hline 3 & variant 3 & 17.0 & 23.5 & 18.3 & 69.8 \\
\hline 4 & variant 4 & 21.6 & 27.3 & 22.3 & 55.8 \\
\hline 5 & variant 5 & 17.6 & 23.8 & 18.7 & 68.8 \\
\hline
\end{tabular}

Figure 4 presents the distribution of air temperature in the hall for the selected hot week and the five variants analyzed. The largest differences between the charts, amounting to $7.7 \mathrm{~K}$, occur in the early morning hours.

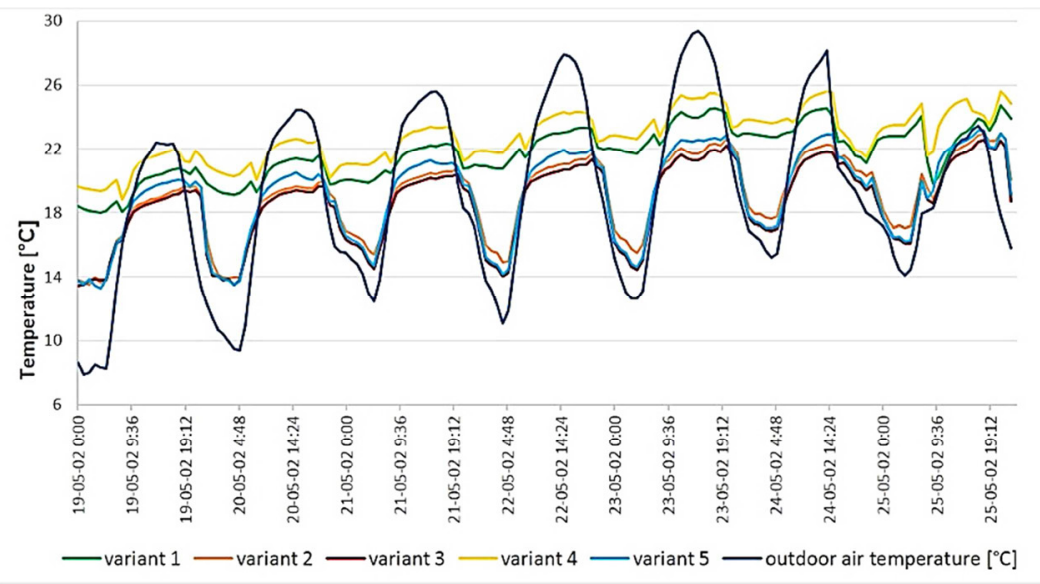

Fig. 4. Distribution of indoor air temperature for the selected week (19.05-25.05)

Variants 1 and 4 do not use night ventilation. As a result, the charts for these variants are much higher on the temperature axis compared to the other three cases. Assuming an air temperature range of comfortable conditions of $14-18^{\circ} \mathrm{C}$, the thermal conditions inside the 
hall in both variant 1 (green graph) and variant 4 (yellow graph) are located outside this zone virtually throughout the entire week. The lowest temperature values are observed in variant 3 , in which mechanical ventilation is turned off during the day, and at night the windows are tilted at $40 \%$ of total opening. The difference during the day is approx. $0.6 \mathrm{~K}$ compared to variant 2 (20\% tilting at night) and $3.9 \mathrm{~K}$ compared to the worst - variant 4 (yellow graph).

However, the most reliable way to assess the thermal conditions in a room is the PMV index, which synthetically combines all forms of heat exchange between the human body and the environment. The highest number of hours in the thermal comfort range ($0.5 \leq \mathrm{PMV} \leq 0.5$ ), amounting to $979 \mathrm{~h}$, occurs in the case of variant 3 , i.e. with mechanical ventilation switched off, but with the use of natural cooling at night $40 \%$ (Table 4). All cases where night ventilation is used, i.e. variants 2, 3 and 5, are more favorable than the other two. The differences in the number of hours that meet the criteria of thermal comfort among individual variants are from 306 to $539 \mathrm{~h}$ (Table 4), which translates into 13-22 more comfortable days during the two-month period.

In variant 4 , when mechanical ventilation is used during the day, but the windows are not tilted at night, it results in the fewest hours with conditions in the thermal comfort zone. The inflow of warm air masses during the day and the inability to cool the facility at night mean that prevailing conditions in the hall exceed the PMV limit value $=0.5$ for $30 \%$ of the entire period. Variant 1 is also characterized by the lack of appropriate microclimatic conditions, in which only for $673 \mathrm{~h}$ out of $1464 \mathrm{~h}$ retain thermal comfort conditions, which represents $54 \%$ of the entire period.

Table 4. Hourly distribution of the PMV index for the adopted simulation variants

\begin{tabular}{|c|c|c|c|}
\hline No. & Simulation variants & $\begin{array}{c}\text { number of hours in the } \\
\text { thermal comfort range - } \\
\mathbf{0 , 5}<\mathbf{P M V}<+\mathbf{0 , 5}\end{array}$ & $\begin{array}{c}\text { number of hours with } \\
\text { index PMV }>\mathbf{0 , 5}\end{array}$ \\
\hline 1 & variant 1 & 673 & 791 \\
\hline 2 & variant 2 & 949 & 405 \\
\hline 3 & variant 3 & 979 & 324 \\
\hline 4 & variant 4 & 440 & 1024 \\
\hline 5 & variant 5 & 963 & 403 \\
\hline
\end{tabular}

Figure 5 presents the distribution of the PMV index for a selected week from the analyzed two-month period. The charts for variants 1 and 4 , when no natural night-time cooling of the building is used, are noticeably above the other charts (Fig. 5). Variants with the use of night ventilation, i.e. 2, 3 and 5, have a PMV index much closer to the comfort zone. The difference in the values of the PMV index among these variants and the worst case No. 4 (yellow chart) is about 1.2 at night and 0.5 at day (Fig. 5). 


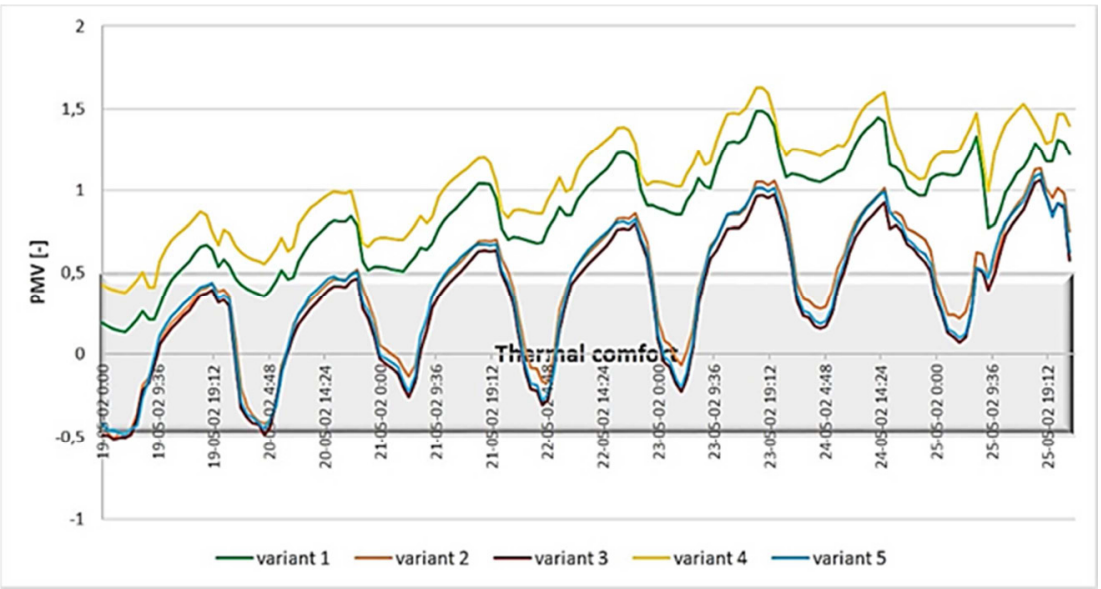

Fig. 5. Distribution of PMV index for the week (19.05-25.05)

The lowest PMV values occur in the case of variant 3 (red graph), when mechanical ventilation is not used during the day, and at night the windows are tilted $40 \%$ of full opening. A small difference in PMV values of 0.1 in relation to variant 3 applies to variant 5 (blue graph), where mechanical ventilation is switched on during the day (minimum required, i.e. $20 \%$ of the maximum value), but natural nighttime cooling (40\% tilt) is the same for the two variants $40 \%$. Variant No. 2 (orange graph) also has a course similar to Variant No. 3, due to similar output parameters. The differences at night are due to the increased percentage of tilt of windows (from 20\% to 40\%) and thus more intense natural air exchange in Variant No. 3.

\section{Summary}

The simulations carried out regarding the impact of night ventilation and mechanical ventilation on thermal comfort in the interior of a passive sports hall in Cracow allowed the formulation of the following conclusions:

- Night ventilation is an effective way to minimize overheating in the summer. Although it was not possible to achieve thermal comfort in the entire analyzed range in this way, night ventilation significantly shortened the period of discomfort.

- On hot days, ventilation should be limited to the minimum required level when temperatures are the highest.

- Natural ventilation is recommended in the early morning and evening, when the outside air temperatures are close to the comfort range for the hall $14-18^{\circ} \mathrm{C}$.

- The most favorable conditions were achieved in the case of variant 3 , with mechanical ventilation switched on during the day at the minimum required level and intensive natural night ventilation (40\% of total window opening).

- At the same time, it should be noted that the degree of opening windows during the night has little effect on the achieved conditions. A smaller window tilt can be of great practical importance in conditions of driving rain or strong wind.

- Natural ventilation in a building with a large cubature is more effective due to the greater intensity of exchanges in relation to the assumed mechanical ventilation, the designed efficiency of which depends on the number of users. Natural ventilation supports also building sustainability. 


\section{References}

1. S. Elba, A. Sangalli., L. IOP Conf. Ser. Earth Environ. Sci., 296 (2019)

2. E. Solgi, Z. Hamedani, R. Fernando, H. Skates, N.E. Orji, Energ. Buildings 173, $337-$ 352 (2018)

3. A. Janssens, H. Breesch, Reliable design of natural night ventilation using building simulation, ASHRAE (2007)

4. J.U. Pfafferott, S. Herkel, M. Wambsganß, Energ. Buildings 36, 455-465 (2004)

5. S. Firth, M. Cook, Natural ventilation in UK schools: design for passive cooling, proceedings of Conference: Adapting to Change: New Thinking on Comfort, (London 2010)

6. P. Tymkow, S. Tassou, M. Kolokotroni., H. Jouhara, Building services design for energy efficient buildings, Routledge, (New York 2013) 